\title{
QUALIDADE DA ÁGUA: FATOS E MITOS!
}

\author{
Water Quality: facts and myths! \\ Calidad del agua: ¡hechos y mitos! \\ Rafael Queiroz de Souza', Kazuko Uchikawa Graziano²
}

RESUMO: Objetivo: Discorrer sobre a importância da água no Centro de Material e Esterilização, sobre as principais evidências de risco, normas, legislação relacionada e orientações para a definição de um sistema de tratamento de água para enxágue de produtos. Método: Revisão narrativa buscando fatos, mitos e descrevendo aspectos relacionados à necessidade de controle da qualidade de água utilizada no processamento de produtos para a saúde. Resultados: Relatos de efeitos tóxicos locais e reações pirogênicas em pacientes demandam a padronização e o controle de qualidade da água para enxágue de produtos e geração de vapor nas autoclaves. Conclusão: O tratamento e o monitoramento da qualidade da água devem ser incorporados pelos serviços de saúde.

Palavras-chave: Instrumentos cirúrgicos. Esterilização. Qualidade da água.

ABSTRACT: Objective: To discuss the importance of water in Central Sterile Services Department (CSSD) and the main evidence of risks, standards, related legislation, and guidelines to develop a water treatment system to rinse products. Method: A narrative review to investigate both facts and myths and to describe the aspects related to the need to control the quality of the water used to process medical devices. Results: Reports of local toxic effects and pyrogenic reactions in patients require the standardization and quality control of water to rinse products and steam generation in autoclaves. Conclusion: Water treatment and quality monitoring should be incorporated by health services.

Keywords: Surgical instruments. Sterilization. Water quality.

RESUMEN: Objetivo: Analizar la importancia del agua en el Centro de Material y Esterilización, sobre las principales evidencias de riesgo, normas, legislación relacionada y orientaciones para la definición de un sistema de tratamiento de agua para enjuague de productos. Método: Revisión narrativa buscando hechos, mitos y describiendo aspectos relacionados a la necesidad de control de la calidad del agua utilizada en el procesamiento de productos para la salud. Resultados: Relatos de efectos tóxicos locales y reacciones pirógenas en pacientes demandan la estandarización y el control de la calidad del agua para enjuague de productos y generación de vapor en las autoclaves. Conclusión: El tratamiento y el monitoreo de la calidad del agua deben ser incorporados por los servicios de salud.

Palabras clave: Instrumentos quirúrgicos. Esterilización. Calidad del agua. 


\section{INTRODUÇÃo}

Em 2012, a Resolução da Diretoria Colegiada (RDC), $n^{\circ}$ 15, da Agência Nacional de Vigilância Sanitária (ANVISA) ${ }^{1}$ estabeleceu que o enxágue dos produtos para saúde deve ser realizado com água que atenda aos padrões de potabilidade, definidos em normatização específica - nesse caso, a Portaria $n^{\circ} 2.914$, de 12 de dezembro de $2011^{2}$, que dispõe sobre os procedimentos de controle e de vigilância da qualidade da água para consumo humano e seu padrão de potabilidade. Além disso, determinou que o enxágue final de produtos críticos utilizados em cirurgias de implantes ortopédicos, oftalmológicos, cirurgias cardíacas e neurológicas deve ser realizado com água purificada, com monitoramento e registro, em periodicidade definida em protocolo, da qualidade da água. Esse monitoramento deve incluir a mensuração da dureza da água, $\mathrm{pH}$, íons cloreto, cobre, ferro, manganês e da carga microbiana nos pontos de enxágue da área de limpeza; porém, sem definição de padrões microbiológicos e físico-químicos de aceitabilidade.

Essas medidas não são mitos, uma vez que a literatura apresenta vários relatos de toxicidade relacionados à qualidade da água no processamento de produtos para saúde. Holland et al. ${ }^{3}$ levantaram a hipótese sobre a associação da ocorrência de ceratite lamelar difusa em pacientes submetidos à cirurgia ocular e a liberação de endotoxinas pelo biofilme presente no reservatório de autoclaves. A investigação do surto envolvendo 52 pacientes revelou a presença de biofilme no reservatório das autoclaves. A adoção de estratégias para o controle de biofilmes no reservatório, que incluíram a limpeza com água fervente, escovação e aplicação de álcool isopropílico a 70\%, resultou na diminuição significativa dos casos.

As endotoxinas podem causar a síndrome tóxica do segmento anterior ocular ${ }^{4,5}$, como também induzir a ocorrência de solturas assépticas em implantes ortopédicos, trazendo consequências graves aos pacientes ${ }^{6}$. Além desses, há também relatos de reações pirogênicas em pacientes que utilizaram cateteres cardíacos reprocessados com água sem controle de microrganismos e endotoxinas ${ }^{7}$.

No Brasil, embora o controle da qualidade microbiológica e físico-química da água seja requerido, não há definições quanto aos parâmetros aceitáveis. Isso posto, sugere-se que o padrão de qualidade de água para enxágue final, para fins de cumprimento de legislação, seja pautado no Technical Information Report 34 de 2007, publicado pela Association for the Advancement of Medical Instrumentation (AAMI) (Quadro 1), ressaltando que, apesar de não exigido pela RDC ANVISA $n^{\circ} 15^{1}$, o padrão deve incluir também o controle de endotoxinas e outros contaminantes requeridos pelos fabricantes de equipamentos e instrumentos cirúrgicos.

Visando uma estimativa concreta do real impacto da qualidade da água na segurança do processamento de produtos para saúde, um estudo avaliou a citotoxicidade de cânulas de hidrodissecção submetidas à contaminação

Quadro 1. Caracterização físico-química e microbiológica da água para processamento de produtos para saúde, de acordo com o Technical Information Report 34 de 2007 da Association for the Advancement of Medical Instrumentation (AAMI)*.

\begin{tabular}{|c|c|c|c|c|}
\hline Contaminantes & Água potável & Água mole & Água deionizada & Água de alta pureza** \\
\hline Bactérias (UFC/mL) & $<200$ & $<200$ & $<200$ & $\leq 10$ \\
\hline Endotoxinas (UE/mL) & NA & NA & NA & $<10$ \\
\hline Carbono orgânico total (mg/L) & $<1,0$ & $<1,0$ & $<1,0$ & $<0,05$ \\
\hline $\mathrm{pH}$ & 6,5 a 8,5 & 6,5 a 8,5 & NA & NA \\
\hline Dureza $\left(\mathrm{CaCO}_{3}\right.$ em ppm) & $<150$ & $<10,0$ & $<1,0$ & $<1,0$ \\
\hline Resistividade (Mn-cm) & NA & NA & $>1,0$ & $>1,0$ \\
\hline $\begin{array}{l}\text { Sólidos dissolvidos totais } \\
\left(\mathrm{CaCO}_{3} \mathrm{em} \mathrm{mg/L)}\right.\end{array}$ & $<500$ & $<500$ & $<0,4$ & $<0,4$ \\
\hline Cloreto (mg/L) & $<250$ & $<250$ & $<1,0$ & $<0,2$ \\
\hline Ferro (mg/L) & $<0,3$ & $<0,3$ & $<0,2$ & $<0,2$ \\
\hline Cobre (mg/L) & $<0,1$ & $<0,1$ & $<0,1$ & $<0,1$ \\
\hline Manganês (mg/L) & $<0,1$ & $<0,1$ & $<0,1$ & $<0,1$ \\
\hline Cor e turbidez & $\begin{array}{l}\text { Incolor, límpida e sem } \\
\text { resíduos }\end{array}$ & $\begin{array}{l}\text { Incolor, límpida e sem } \\
\text { resíduos }\end{array}$ & $\begin{array}{l}\text { Incolor, límpida e sem } \\
\text { resíduos }\end{array}$ & $\begin{array}{l}\text { Incolor, límpida e sem } \\
\text { resíduos }\end{array}$ \\
\hline
\end{tabular}

*Documento atualizado em 2014, porém, a edição de 2007 apresenta correspondência com os parâmetros exigidos no artigo 74 da RDC ANVISA n. $15^{(1)}$; **Recomendada para o enxágue final; UFC: unidades formadoras de colônias; UE: unidades de endotoxinas; NA: não se aplica. Fonte: Traduzida e adaptada de AAMI, $2007^{\circ}$. 
desafio, limpeza baseada em procedimento operacional padrão (POP) validado e enxágue final em diferentes tipos de água: de torneira, deionizada, destilada, tratada por osmose reversa e ultrapurificada ${ }^{9}$. As amostras foram contaminadas interna e externamente por uma solução contendo $20 \%$ de sangue de carneiro desfibrinado e $80 \%$ de cloreto de sódio a $0,9 \%$. Em seguida, tiveram o lúmen preenchido por solução viscoelástica, permanecendo em contato com o contaminante por 50 minutos, sendo então processadas, de acordo com um POP validado ${ }^{10}$. Os resultados demonstraram que a qualidade da água para o último enxágue, como uma variável isolada, não influencia na citotoxidade das cânulas, porém, essa afirmação só é válida quando assegurada a qualidade da limpeza ${ }^{9}$. Nesse estudo, os autores não recomendaram a utilização de água sem controle de padrões físico-químicos e microbiológicos, pela variação sazonal e geográfica da água ${ }^{11}$ e pela possibilidade de corrosão do instrumental. Outro aspecto levantado pelos autores é que esses resultados não dispensam o controle dos contaminantes do vapor, conforme a segunda parte da norma do American National Standards Institute (ANSI), da Association for the Advancement of Medical Instrumentation (AAMI) e da International Organization Standardization (ISO) 17665-1 ${ }^{12}$.

De acordo com os dados apresentados, conclui-se que a necessidade do controle da qualidade da água no processamento de produtos para saúde é fato; e o monitoramento deve ser incorporado pelos serviços de saúde.

Há diversas tecnologias para tratamento de água no mercado, sendo, portanto, recomendado que os serviços adotem um padrão de qualidade para a água utilizada no último enxágue e dimensionem as tecnologias de tratamento de acordo com a necessidade do Centro de Material e Esterilização, considerando o volume de água necessário e a eficiência do sistema de tratamento. Uma vez que o monitoramento da água deve ser realizado de acordo com um protocolo, recomenda-se que no período após a instalação do sistema sejam realizadas análises com intervalos menores, a fim de se conhecer a efetividade do sistema. De acordo com a constância nos resultados, o monitoramento pode ser menos frequente, pois, com base no histórico dos valores obtidos, pode-se determinar a necessidade de troca de consumíveis e a manutenção preventiva do sistema de tratamento, visando à manutenção do padrão de qualidade da água tratada.

\section{REFERÊNCIAS}

1. Brasil. Resolução da Diretoria Colegiada no 15, de 15 de março de 2012. Dispõe sobre requisitos de boas práticas para o processamento de produtos para saúde e dá outras providências. Brasília: Ministério da Saúde; 2012 [citado 2015 mar 27]. Disponível em: http://bvsms.saude. gov.br/bvs/saudelegis/anvisa/2012/rdc0015_15_03_2012.html

2. Brasil. Portaria $\mathrm{n}^{\circ} 2.914$ de 12 de dezembro de 2011 . Dispõe sobre os procedimentos de controle e de vigilância da qualidade da água para consumo humano e seu padrão de potabilidade. Brasília: Ministério da Saúde; 2011.

3. Holland SP, Mathias RG, Morck DW, Chiu J, Slade SG. Diffuse lamellar keratitis related to endotoxins released from sterilizer reservoir biofilms. Ophthalmology. 2000;107(7):1227-33.

4. Johnston J. Toxic anterior segment syndrome: more than sterility meets the eye. AORN J. 2006;84(6):969-84; quiz 985-6.

5. Mamalis N, Edelhauser HF, Dawson DG, Chew J, LeBoyer RM, Werner L. Toxic anterior segment syndrome. J Cataract Refract Surg. 2006;32(2):324-33.

6. Greenfield EM, Bi Y, Ragab AA, Goldberg VM, Nalepka JL, Seabold JM. Does endotoxin contribute to aseptic loosening of orthopedic implants? J Biomed Mater Res B Appl Biomater. 2005;72(1):179-85.
7. Ribeiro SMCP, Graziano KU, Alfa MM, Goveia VR. Reprocessamento de cateteres cardíacos: uma revisão. Rev Bras Cir Cardiovasc. 2006;21(3):334-42.

8. Association for the Advancement of Medical Instrumentation. Water for the reprocessing of medical devices. Arlington: AAMI; 2007. AAMI Technical Information Report 34.

9. Souza RQ, Gonçalves CR, Ikeda TI, Cruz AS, Graziano KU. O impacto do último enxágue na citotoxicidade de produtos críticos passíveis de processamento. Rev Esc Enferm USP. 2015;49(spe):87-92.

10. Tamashiro NS, Souza RQ, Gonçalves CR, Ikeda TI, Luz RA, Cruz AS, et al. Cytotoxicity of cannulas for ophthalmic surgery after cleaning and sterilization: evaluation of the use of enzymatic detergent to remove residual ophthalmic viscosurgical device material. J Cataract Refract Surg. 2013;39(6):937-41.

11. Association of Perioperative Registered Nurses. Perioperative standards and recommended practices. Denver: AORN; 2013.

12. International Organization Standardization. ANSI/AAMI/ISO 17665-1. Sterilization of health care products - Moist heat Part 2: Guidance on the application of ANSI/AAMI/ISO 17665-1. Geneva: ISO; 2009. 